\title{
Systematic Review of Enhancement of Artificial Bee Colony Algorithm Using Ant Colony Pheromone
}

\author{
https://doi.org/10.3991/ijim.v15i16.24171 \\ Abdul Hadi Alaidi ${ }^{(凶)}$, Chen Soong Der, Yeng Weng Leong \\ Universiti Tenaga Nasional, Malaysia \\ alaidi@uowasit.edu.iq
}

\begin{abstract}
The artificial bee colony (ABC) is a well-studied algorithm developed to solve continuous function optimization problems by Karboga and Akay in 2009. ABC has been proven to be more effective than other biological-inspired algorithms with good exploration. However, $\mathrm{ABC}$ suffers from low exploitation and slow convergence in some cases. The $\mathrm{ABC}$ algorithm study has risen significantly over the past decade, with many researchers trying to improve $\mathrm{ABC}$ performance and apply it to solve problems. One method to enhance $A B C$ is to borrow exploration technique from other algorithms. Researchers use pheromone, which is a technique used by Ant Colony optimization algorithm, to enhance $\mathrm{ABC}$ and addressed several aspects of using a pheromone to enhance $\mathrm{ABC}$. This systematic review aims to review and analysis articles about using pheromone to enhance ABC. Articles on related topics were systematically searched in four major databases, namely Scopus, Web of Science, Association for Computing Machinery ACM and Google Scholar. To ensure that all research articles were considered the start date is not restrictions the search carry out till February 2021. Five articles were selected based on our inclusion and exclusion criteria for the systematic review. The results show that the use Pheromone to enhance $\mathrm{ABC}$ can increase the $\mathrm{ABC}$ exploitation ability and overcoming the late convergence. This paper also illustrates several potential pheromone using for future work.
\end{abstract}

Keywords — artificial bee colony, pheromone, ant colony

\section{$1 \quad$ Introduction}

The artificial bee colony ( $\mathrm{ABC}$ ) algorithm is a well-studied algorithm developed to handle continuous function optimization issues by Karboga and Akay in 2005 [1]. It mimics the foraging behaviors of a swarm of bees to find food. ABC successfully used in many fields like Management of energy for mobile devices [2], [3] and for routing of Mobile Agents on IoT [4], [5]. The artificial bee colony is divided into three groups: employed, onlookers, and scouts' bees. First, employed bee's exploration for food sources and share the knowledge with an onlooker bee. Using the knowledge given down from the employed bee, the onlooker bee seeks to identify a better food source in the neighborhood. The onlooker bees abandoned the food source and becomes a scout bee if and only if the food source enhancement exceed a defined limitation. A scout bee 
and randomly seek for a new food source. In ABC, the exploitation is accomplished by both onlooker and employed bees, while the exploration process control by scout bees.

In $\mathrm{ABC}$, the employed bees used the equation (1) for searching neighbors by moving from an old position $x_{i j}$ to the new position $v_{i j}$ if and only if the fitness of new position's is better than the fitness of the old position.

$$
v_{i j}=x_{i j}+\phi_{i j}\left(x_{i j}-x_{k j}\right)
$$

Where $x_{i}$ is the old position and $v_{i}$ is the new position of $i^{\text {th }}$ employed. $\phi_{i j}$ is a random number between $[-1,1], j$ is an arbitrary integer number between 1 and dimension of the problem, while $k$ is a random number between the number of bees employed and 1 . On the other hand, the onlooker bee selects food depending on the probability that calculated by equation 2 and evaluate all employed bee

$$
p_{i}=\frac{f i t_{i}}{\sum_{j=1}^{S N} f i t_{j}}
$$

Where fit is the fitness values of the solution of employed bee, and it calculates using equation 3

$$
f i t_{i}=\left\{\begin{array}{l}
\frac{1}{1+f\left(x_{i}\right)}, f\left(x_{i}\right) \geq 0 \\
1+\left|f\left(x_{i}\right)\right|, f\left(x_{i}\right)<0
\end{array}\right.
$$

Where $f\left(x_{i}\right)$ stands for the value of the objective function to be optimized. Like the employed bee, the onlooker bee uses equation 1 to update the position and explore the selected food source.

The food source will be abandoned if it cannot be further enhanced within a pre-defined condition, then the employed randomly explore for a new food source and call it scout bee.

Such a combination of exploration and exploitation search in ABC is important. It enables the algorithm to search over the solution space for high-quality solutions and prevent them from getting trapped in local optima. In $\mathrm{ABC}$, the employed bees maintain the current solution while the onlooker bees allow the best solution to be exploited. Furthermore, scout bees try to remove stagnating solutions and explore new solutions.

$\mathrm{ABC}$ method has been successfully used to solve a wide range of hard combinational issues. One of these problems is the traveling salesman problem where the salesman attempts to find the shortest possible tour by visiting a set of customer cities. ABC is considered one of the best algorithms among other available algorithms to solve TSP [6]. Algorithm 1 shows the pseudo-code of the artificial bee colony algorithm.

Algorithm 1 The standard Artificial bee colony (ABC).

1. Initialization Phase

2. REPEAT

3. Employed Bees Phase

4. Onlooker Bees Phase

5. Scout Bees Phase

6. Memorize the best solution achieved so far

7. UNTIL (Cycle $=$ Maximum Cycle Number or a Maximum CPU time) 
Another non-deterministic algorithm used to solve the optimization issues is the Ant Colony Optimization algorithm (ACO). In 1992, Marco Dorigo proposed Ant Colony Optimization (ACO), which was inspired by ants seeking the shortest path between a source food and their colony [7], [8]. ACO seeks the optimal solution for the computation problem by building one solution and adding this solution-to-solution component until the wanted solution is built. Ant colony optimization successfully applied to solve the travelling salesman problem. The accuracy of the ACO algorithm, on the other hand, decreases as the problem's complexity rises. In nature, ants use pheromone as indirect communication between them. In ACO, pheromones are represented by numeric values, which are modified by every solution component; these values influence the movement of ants in the next iteration in a way that edges between nodes with large values (a high level of pheromone) are more likely to be visited. Besides, the ACO model allows to include heuristic information to guide ants to complete a feasible solution.

In this study, a systematic literature review is carried out to characterize relevant studies regarding the use of pheromone to enhance the artificial bee colony.

\section{Methodology}

In academic research, Systematic literature review (SLR) may use for validate models thus improving methodological progress and consistency along with the ability to find gaps for further studies [9]. The main research questions addressed in this study are;

1. How to use pheromone to enhance $\mathrm{ABC}$ ?

2. How to integrate ACO with $\mathrm{ABC}$ ?

3 . Is there any researcher used pheromone to increase the exploration of $\mathrm{ABC}$ ?

All articles with enhancing or improve artificial bee colony use pheromone was carried out were identified through four world-renown bibliographic databases: Scopus, Web of Science (WoS), Association for Computing Machinery (ACM), and Google Scholar (GS) using the search string in Table 1.

Table 1. Search terms

\begin{tabular}{|c|c|}
\hline $\begin{array}{l}\text { Bibliographic } \\
\text { Database }\end{array}$ & Search Terms \\
\hline Scopus & $\begin{array}{l}\text { TITLE (“Artificial bee colony") AND ALL (pheromone AND } \\
\text { (improve* OR enhance* OR exploration OR exploitation)) }\end{array}$ \\
\hline WoS & $\begin{array}{l}\# 1 \mathrm{TS}=\text { (improve* OR enhance* OR exploration OR exploitation) } \\
\# 2 \mathrm{TS}=(\text { Artificial bee colony }) \\
\# 3 \text { TS }=\text { (pheromone) } \\
\# 4 \text { \#1 AND \#2 AND \#3 }\end{array}$ \\
\hline $\mathrm{ACM}$ & $\begin{array}{l}\text { "artificial bee colony" AND pheromone AND (improve* OR enhance* } \\
\text { OR exploration OR exploitation) }\end{array}$ \\
\hline GS & allintitle: pheromone "Artificial bee colony" \\
\hline
\end{tabular}

A published article is included if: (1) it is a peer-reviewed research article written in English; (2) it is on artificial bee colony and pheromone. No date restrictions are 
imposed. The search was conducted in February 2021 to ensure that all research articles were considered.

\subsection{Selection of study}

This phase is starting with initial search that is generating 86 articles. After duplicate removal (seven articles) all studies were screened using the Rayyan. Three phases come after this one, the phases are screening, filtering as well as initiating of category for determining if the created articles might be involved in the review or not. In addition, the duplicated articles have been specified and removed from different data-bases. Title in addition to abstract scanning are used for determining the relevance regarding all articles, that have been later categorized in various folders on the basis of their similarities and attributes, while the second filtering phase is commenced through carrying out complete full-text reading related to the screened articles from the first phase, also the third phase included deep examination regarding articles for determining adequate main and sub-categories. Many comments and notes have been taken throughout the process. Figure 1 show the search, screening and selection process for suitable studies.

\subsection{Using pheromone}

One of the Artificial bee colony problem is blindness search strategy for food source. [10], [11] use attraction pheromone and transition strategy to solve the blindness search. Honey bees primarily interact with each other in nature through behavioral communication and communication with chemistry. Honey bees only dance to exchange information in the traditional artificial bee colony algorithm (conduct communication). To correspond with reality in nature and the $\mathrm{ABC}$ principle, it is vital and sensible to include chemical communication must be combined with behavioral communication. More specifically, the authors assume that each bee travel to a food source and deposits an attraction pheromone on solution, causing other bees to attract to the object where pheromone strength is higher than other This technique allows bees to look for food in a more efficient manner.

Multidimensional Knapsack problem (MKPs) can define as given a set $j=\left\{o_{1}\right.$, $\left.o_{2}, \ldots, o_{n}\right\}$ of $n$ items and knapsack with a set $C=\left\{c_{1}, c_{2}, \ldots c_{m}\right\}$ of $m$ dimension, the $0-1$ Multidimensional Knapsack problem search for a subgroup of $J$ in where the total profit of items included in the subgroup is maximized, while $m$ resource constraint remains fulfilled. The following is the formulation of MKP_01:

$$
\begin{aligned}
& \text { Maximize } \sum_{j=1}^{n} p_{j} x_{j} \\
& \text { Subject to } \sum_{j=1}^{n} r_{i j} x_{j} \leq c_{i} \quad i=1, \ldots, m \\
& x_{j} \in\{0,1\}, \quad j=1, \ldots, n
\end{aligned}
$$




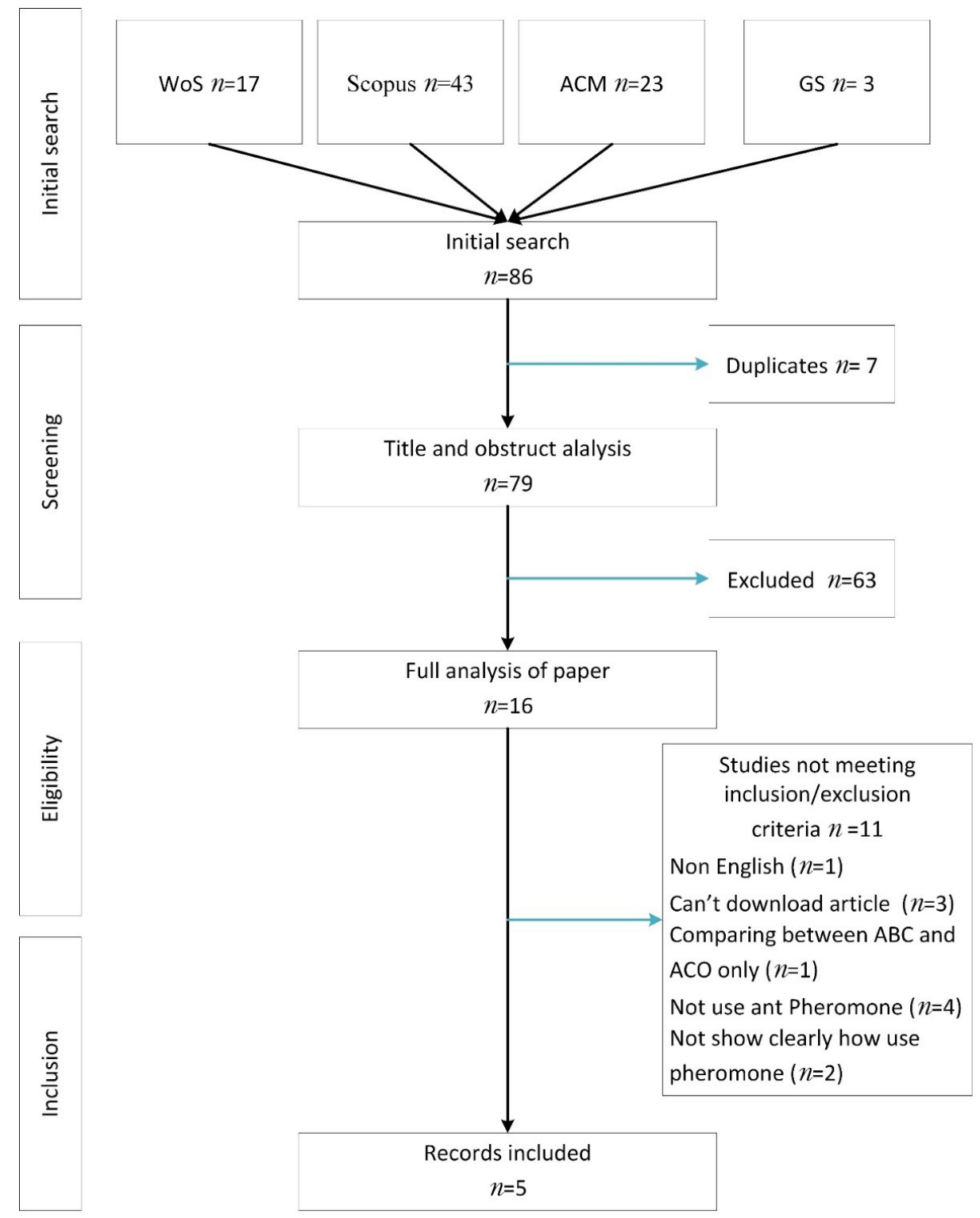

Fig. 1. The process of searching, screening and selecting the suitable studies

MKPs solved using the artificial bee colony with pheromone communication (ABCPUD-MKP) where transition probability value reflects a trade-off between pseudo utility and the strength of pheromones. That is, with a high probability, those items which consume fewer resources and have more benefit would be selected. Yet, if an item is used in several solutions, it is extremely attractive because of the high strength of pheromones [11] combine two strategies to update pheromone. The first 
one is to lay pheromone trails on each item pick which led to select objects that occur frequently in solution. The second method is to lay pheromone on each pair of different items. In addition, in ABCPUD-MKP employee bees are responsible for update pheromone and scout bees use pheromone and some heuristic information as a guide for looking for new food sources.

ABCPUD-MKP is a hybrid algorithm that uses two ways of communication between bees. The employee and onlooker bees progressively enhance their related solutions in solution neighbors as the iteration runs on the basis of the behavior communication process. The scout bees, on the other hand, devised new solutions in light of the chemical communication method, which uses the pheromone collected by bees to induct item selection. ABC-MKP is different than ABCPUD-MKP in two phases: the discovery of new solution and the production, dissemination and upgrading of pheromones used only by the ABCPUD-MKP. To generate a good quality solution, employee bees use the heuristic information and the transformation probability based on pheromone paths.

[12] use a pheromone to enhance the convergence of artificial bee colony. In addition, to boost ABC's efficiency in terms of local search capabilities. pheromone approach of ACO used and hybrid metaheuristic method developed as an enhanced version of $\mathrm{ABC}$ which called $\mathrm{pABC}$. In the principle of the $\mathrm{pABC}$ algorithm, to make honey, bees' objective is to fetch the finest food to the hive. Employed bees gather pollen from the flowers of related flowers in the neighbor area and bring the food they receive to the hive. Employed bees secrete pheromones between the flowers they visit in the process of gathering pollen. Subsequently, onlooker bees choose flowers based on the amount of pheromone quantity. The food in the pABC algorithm is composed of pollen obtained from various types of flowers.

Ant colony optimization combined with the artificial bee colony by [13] (ABA) to design a fuzzy expert system with membership function and if-then rules. The author uses ant colony algorithm to evaluate the rule which is set using integer numbers in microarray gene expression data. Moreover, ACO used in parallel with ABC so actually there is no combining between $\mathrm{ACO}$ and $\mathrm{ABC}$ or using pheromone to enhance $\mathrm{ABC}$.

Another studies use ABC for gen selection and cancer classification proposed by [14]. Pheromone used to overcome the limitation of $\mathrm{ABC}$ exploitation by making bees communicate and share their finding. Scout bees use pheromone as a guide when searching for new food source and pheromone update in all stages. Moreover, the amount of deposit pheromone is a function of fitness measures.

\section{Discussion}

Using pheromone with an artificial bee colony will increase and balance exploration and exploitation. Moreover, using pheromone intends to speed up the convergence of the algorithm. However, there are many ways to use pheromone to enhance the artificial bee colony.

Table 2 shows the difference in using pheromone to enhance artificial bee colony. The pheromone initializes in all algorithm is same where the initial value of pheromone is a constant value and same for all different problem that algorithm solve. In addition, the bee will update pheromone after each stage except for [13] where in 
addition to update in all stages the best so far is also update the pheromone and in [12] the employee bee will update the pheromone after each cycle. Moreover, the deposit pheromone amount is different in all algorithms were in [14] used function of fitness to update pheromone while in [12] used objective function as accumulative to update pheromone. On other hand, [11] uses the solutions obtained at each iteration to increase pheromone while [13] selects the best path to update the pheromone.

Table 2. Using pheromone comparison

\begin{tabular}{|l|l|l|l|l|}
\hline Method & \multicolumn{1}{|c|}{$\begin{array}{c}\text { Pheromone } \\
\text { Initialization }\end{array}$} & \multicolumn{1}{|c|}{$\begin{array}{c}\text { Pheromone } \\
\text { Update }\end{array}$} & \multicolumn{1}{|c|}{$\begin{array}{c}\text { Pheromone } \\
\text { Deposit }\end{array}$} & \multicolumn{1}{|c|}{ Selection } \\
\hline$[14]$ & $\begin{array}{l}\text { Initial to constant } \\
\text { value (tmax) }\end{array}$ & $\begin{array}{l}\text { Update pheromone } \\
\text { in all bee stages }\end{array}$ & $\begin{array}{l}\text { Function of fitness } \\
\text { measures }\end{array}$ & $\begin{array}{l}\text { Scout bee use pheromone } \\
\text { to explore for new food } \\
\text { source }\end{array}$ \\
\hline$[11]$ & $\begin{array}{l}\text { Initial to constant } \\
\text { value }\end{array}$ & $\begin{array}{l}\text { Update pheromone } \\
\text { in all bee stages }\end{array}$ & $\begin{array}{l}\text { Use solutions } \\
\text { acquired at } \\
\text { every iteration } \\
\text { to accumulate } \\
\text { pheromone }\end{array}$ & $\begin{array}{l}\text { Construct new solutions } \\
\text { using pheromone trails and } \\
\text { heuristic information }\end{array}$ \\
\hline$[13]$ & $\begin{array}{l}\text { Initial to constant } \\
\text { value }\end{array}$ & $\begin{array}{l}\text { Local pheromone } \\
\text { update rule and } \\
\text { best so far update }\end{array}$ & $\begin{array}{l}\text { Updated on the } \\
\text { selected best path }\end{array}$ & $\begin{array}{l}\text { Split the search space to } \\
\text { ACO and ABC }\end{array}$ \\
\hline$[12]$ & $\begin{array}{l}\text { Initial to small } \\
\text { positive constant }\end{array}$ & $\begin{array}{l}\text { After each cycle } \\
\text { all employed } \\
\text { bees updating } \\
\text { the phenomenon }\end{array}$ & $\begin{array}{l}\text { Pheromone amounts } \\
\text { are determined as } \\
\text { objective function }\end{array}$ & $\begin{array}{l}\text { 1-Selected from best } \\
\text { candidate in terms of the } \\
\text { attractiveness. } \\
\text { 2-Use the probability } \\
\text { distribution which is based } \\
\text { on the pheromone amounts }\end{array}$ \\
\hline
\end{tabular}

\section{Conclusion}

In this research, studies about using pheromone to enhance the artificial bee colony algorithm were systematically reviewed. The results reveal that using pheromone to enhance $\mathrm{ABC}$ is different in main three aspects. The first difference is how pheromone update and when it updates. Moreover, how pheromone deposit is the second main difference. The final main difference between the use of pheromone to enhance $A B C$ is the mechanism used to select the new solution. In future work, an enhanced $\mathrm{ABC}$ using pheromone will be designed by changing the initial value and use the neighbor algorithm for initialization. The second update pheromone will be done in scout bee phase only. Moreover, the decrease of pheromone amount on the edge joins two parts by a constant factor. Then put a certain amount of pheromone on that particular edge. Finally, the selection mechanism will depend on pheromone OR neighbor list OR random which will increase the exploration and enhance the exploitation of Artificial bee colony.

\section{$5 \quad$ Acknowledgment}

The authors significantly acknowledged the financial support from Universiti Tenaga Nasional under UNITEN-Iraq scholarships. 
[1] D. Karaboga and B. Basturk, "A powerful and efficient algorithm for numerical function optimization: artificial bee colony (ABC) algorithm," J. Glob. Optim., vol. 39, no. 3, pp. 459-471, 2007. https://doi.org/10.1007/s10898-007-9149-x

[2] S. ArunKumar, B. V. Kumar, and M. Pandi, "Artificial bee colony optimization based energy-efficient wireless network interface selection for industrial mobile devices," Comput. Commun., vol. 154, pp. 1-10, 2020. https://doi.org/10.1016/j.comcom.2020.01.067

[3] I. Hamad and M. Hasan, "A review: On using ACO based hybrid algorithms for path planning of Multi-Mobile Robotics," international journal of interactive mobile technologies, vol. 14, no. 18, pp. 145-156, 2020. https://doi.org/10.3991/ijim.v14i18.16371

[4] S. Yousefi, F. Derakhshan, and H. Karimipour, "Artificial Bee Colony-based Routing for Mobile Agents on the Internet of Things," in 2020 IEEE Electric Power and Energy Conference (EPEC), 2020, pp. 1-5. https://doi.org/10.1109/EPEC48502.2020.9320053

[5] J. Fang, "Clustering and Path Planning for Wireless Sensor Networks based on Improved Ant Colony Algorithm.," International Journal of Online \& Biomedical Engineering, vol. 15, no. 1, 2019. https://doi.org/10.3991/ijoe.v15i01.9784

[6] S. S. Choong, L.-P. Wong, and C. P. Lim, "An artificial bee colony algorithm with a modified choice function for the traveling salesman problem," Swarm Evol. Comput., vol. 44, pp. 622-635, 2019. https://doi.org/10.1016/j.swevo.2018.08.004

[7] M. Dorigo and M. Birattari, "Ant colony optimization," in Encyclopedia of Machine Learning, Springer, 2010, pp. 36-39. https://doi.org/10.1007/978-0-387-30164-8 22

[8] H. Mustafa, "Mathematical Modeling of Cooperative E-Learning Performance in Face to Face Tutoring (Ant Colony System Approach)," International Journal of Advanced Corporate Learning (iJAC), vol. 3, no. 4, pp. 13-20, 2010. https://doi.org/10.3991/ijac.v3i4.1471

[9] A. Cherp, V. Vinichenko, J. Jewell, E. Brutschin, and B. Sovacool, "Integrating techno-economic, socio-technical and political perspectives on national energy transitions: A meta-theoretical framework," Energy Res. Soc. Sci., vol. 37, pp. 175-190, 2018. https://doi. org/10.1016/j.erss.2017.09.015

[10] H. Wei, J. Ji, Y. Qin, Y. Wang, and C. Liu, " $\{$ A novel artificial bee colony algorithm based on attraction pheromone for the multidimensional knapsack problems\} - International Conference on Artificial Intelligence and Computational Intelligence," pp. 1-10, 2011. https://doi. org/10.1007/978-3-642-23887-1_1

[11] J. Ji, H. Wei, C. Liu, and B. Yin, "Artificial bee colony algorithm merged with pheromone communication mechanism for the 0-1 multidimensional knapsack problem," Math. Probl. Eng., vol. 2013, 2013. https://doi.org/10.1155/2013/676275

[12] D. Ekmekci, "A Pheromonal Artificial Bee Colony -pABC- Algorithm for Optimization Problems," in 2019 16TH INTERNATIONAL MULTI-CONFERENCE ON SYSTEMS, SIGNALS \& DEVICES (SSD), 2019, pp. 452-456. https://doi.org/10.1109/SSD.2019.8893259

[13] P. GaneshKumar, C. Rani, D. Devaraj, and T. A. A. Victoire, "Hybrid Ant Bee Algorithm for Fuzzy Expert System Based Sample Classification," IEEE/ACM Trans. Comput. Biol. Bioinforma., vol. 11, no. 2, pp. 347-360, 2014, doi: 10.1109/TCBB.2014.2307325. https://doi.org/10.1109/TCBB.2014.2307325.

[14] J. M. Moosa, R. Shakur, M. Kaykobad, and M. S. Rahman, "Gene selection for cancer classification with the help of bees," BMC Med. Genomics, vol. 9, no. 2, Aug. 2016, doi: https://doi.org/10.1186/s12920-016-0204-7. 


\section{Authors}

Abdul Hadi Mohammed Alaidi finish hi master in. computer science from Bridgeport university, USA. He is currently PhD student at Universiti Tenaga Nasional, Malaysia.alaidi@uowasit.edu.iq

Chen Soong Der currently working as Associate Professor at Universiti Tenaga Nasional, Malaysia. He has completed his Ph.D. in Image Enhancement from the same University. He is a professional member of the Institute of Electrical and Electronics Engineers.

Yeng Weng Leong currently working as Senior Lecturer at Universiti Tenaga Nasional, Malaysia. He has completed his Ph.D. from Kanazawa University, Japan.

Article submitted 2021-05-27. Resubmitted 2021-06-28. Final acceptance 2021-06-28. Final version published as submitted by the authors. 